\title{
In vitro and in vivo Effects of Metformin on Human Adipose Tissue Adiponectin
}

\author{
Alessandra Zulian ${ }^{a, b}$ Raffaella Cancello ${ }^{b} \quad$ Andrea Girola ${ }^{a} \quad$ Luisa Gilardini ${ }^{a} \quad$ Luisella Alberti $^{a, b}$ \\ Marina Croci $^{a}$ Giancarlo Micheletto ${ }^{c}$ Piergiorgio Danelli ${ }^{d}$ Cecilia Invitti ${ }^{a}$ \\ a Department of Medical Sciences and Rehabilitation, \\ b Laboratory of Molecular Biology, Istituto Auxologico Italiano, \\ ${ }^{c}$ Department of Surgery, University of Milan, \\ ${ }^{\mathrm{d}}$ Department of Clinical Sciences Luigi Sacco, University of Milan, Milan, Italy
}

\section{Keywords}

Adiponectin - Adipose tissue - Metformin - Obesity . Insulin resistance

\section{Summary}

Objective: The effects of metformin on adiponectin production are controversial and have never been investigated in human adipose tissue. We analysed whether metformin modulates, in vitro and in vivo, gene expression, protein content, and secretion of adiponectin. Methods: For the in vitro study, subcutaneous adipose tissue (SAT) and visceral adipose tissue (VAT) samples from 5 non-diabetic obese patients were collected. For the in vivo investigation, 22 obese patients were randomly assigned to metformin+lifestyle $(M L)$ or placebo+lifestyle (PL) intervention. SAT specimens and blood samples were collected before and after the intervention in both groups. Results: In in vitro experiments, treatment with metformin increased the expression and secretion of adiponectin in SAT, but not in VAT explants. In the in vivo study, a significant increase in adiponectin and a decreased expression of a macrophage activation marker (CD68) were observed only in SAT of the ML group. Conclusion: These results demonstrate that metformin is able to up-regulate adiponectin gene expression, both in vivo and in vitro, and to stimulate adiponectin protein secretion from human SAT in vitro. It could be hypothesised that metformin-induced adiponectin increase within adipose tissue may have an unexpected role in the reduction of local inflammation.

\section{Introduction}

Metformin is an insulin sensitizer agent widely used for the therapy of type 2 diabetes. This drug lowers glucose levels mainly by decreasing hepatic glucose production [1, 2]. In addition, metformin ameliorates hyperglycaemia through reduction of lipolysis [3], increase in skeletal muscle glucose uptake $[4,5]$, intestinal glucose utilisation [6], and improvement in beta-cell survival [7]. Increasing evidence suggest that metformin has many other effects independent of its anti-hyperglycaemic action. Examples are the improvement in endothelial function, haemostasis, microvascular flow, oxidative stress, inflammation, inhibition of macrophage lipid accumulation, and cancer cell proliferation [8-10].

Controversial results have been reported on the ability of metformin to influence the endocrine functions of human adipose tissue [11]. In particular, it is unclear whether metformin regulates adiponectin synthesis and secretion. This issue requires a thorough study, because adiponectin modulates a wide number of processes that are also influenced by metformin.

Adiponectin is a protein hormone exclusively secreted by the adipocytes that improves insulin sensitivity and glucose homeostasis by suppressing hepatic glucose production, increasing insulin-mediated glucose uptake by skeletal muscle and promoting fatty acid oxidation $[12,13]$. In addition, adiponectin directly inhibits inflammation, angiogenesis, and tumorigenesis [14-16]. All these effects are mediated through the activation of AMP-activated protein kinase which is also the mediator of metformin actions [13, 17-19]. Although up-regulation of adiponectin expression and secretion by insulin-sensitising agents, such as thiazolidinediones, has been established $[20,21]$, the role of metformin in the modulation of adiponectin expression and secretion is controversial [2, 22-27].

\section{KARGER \\ Fax +497614520714 \\ Information@Karger.de}

www.karger.com (c) 2011 S. Karger GmbH, Freiburg

$1662-4025 / 11 / 0041-0027 \$ 38.00 / 0$

Accessible online at:

www.karger.com/ofa
Cecilia Invitti, MD

Department of Medical Sciences and Rehabilitation,

Istituto Auxologico Italiano,

Via Ariosto 13, 20145 Milan, Italy

Tel. +39 26191125-35, Fax -41

invitti@auxologico.it 
To date, the in vitro effects of metformin on adiponectin synthesis and secretion have never been investigated in human adipose tissue. Therefore, the aim of this study was to evaluate: i) the in vitro effects of metformin on adiponectin expression, intracellular protein content and secretion in human subcutaneous adipose tissue (SAT) and visceral adipose tissue (VAT), as well as in isolated adipocytes differentiated from the stroma-vascular fraction (SVF) cells and ii) the in vivo effects of a short-time metformin+lifestyle (ML) or placebo+lifestyle (PL) intervention on adiponectin and CD68 expression in SAT of obese non-diabetic subjects.

\section{Material and Methods}

\section{Experimental Design}

SAT and VAT specimens were obtained during bariatric surgery interventions from 5 non-diabetic obese subjects (females; BMI $38 \pm 11.57 \mathrm{~kg} / \mathrm{m}^{2}$ $39 \pm 8$ years; mean $\pm \mathrm{SD}$ ) to analyse the in vitro effects of metformin. Two patients of the enrolled 5 had impaired fasting glucose tolerance (IFG; defined by fasting glucose $\geq 100 \mathrm{mg} / \mathrm{dl}$ and $\leq 126 \mathrm{mg} / \mathrm{dl}$ ).

In the in vivo protocol, 150 obese patients without known diabetes were screened who were referred for clinical management to the Istituto Auxologico Italiano, a specialized centre for the treatment and study of obesity.

All patients underwent an oral glucose tolerance test (OGTT) and were considered eligible for the study if they had impaired glucose tolerance (IGT defined by 2-hour glucose $\geq 140$ and $<200 \mathrm{mg} / \mathrm{dl}$ ) or OGTT-diagnosed diabetes (defined by 2-hour glucose $\geq 200 \mathrm{mg} / \mathrm{dl}$ ) or a value $\geq 5$ of homeostasis model assessment of insulin resistance (HOMA-IR). Antidiabetic therapy, liver and renal dysfunction, and/or acute/chronic inflammatory diseases were criteria of exclusion.

After the screening, 24 obese patients were eligible for this study. Patients were submitted to physical examination, blood sample collection for the measurement of HDL cholesterol, triglycerides, insulin and adiponectin, and bio-impedance analysis (BIA-101; RJL Systems, Clinton Township, MI, USA) for body composition assessment.

In all enrolled subjects, a peri-umbilical SAT needle biopsy was performed following the standardised protocol (European Framework 5 project NUGENOB, www.nugenob.com). All patients underwent a 3-month lifestyle intervention that consisted of two educational group sessions/week with nutritionists, dieticians, physical trainers, and psychologists. The alimentary diary was weekly reviewed and discussed. Twice a week patients participated in a 1-hour gym session under a trainer guidance. A questionnaire on the frequency, duration, and/or intensity of housework-, job- and sports-related physical activity was administered [28]. Compliance to the exercise program was classified as insufficient (1), sufficient (2), and good (3) [28].

Patients were randomised through a random number table allocation to receive metformin (850 $\mathrm{mg}$ twice a day) (ML group) or placebo (PL group). Adherence to the treatment regimen was assessed every 2 weeks on the basis of pill counts and interviews. After 3 months of treatment, all baseline assessments including SAT biopsies were repeated. This study was approved by the Ethic Committee of Istituto Auxologico Italiano, and written informed consent was obtained from all subjects after individual explanation.

\section{Cultures of Human White Adipose Tissue Explants}

The SAT samples collected from 5 non-diabetic obese subjects were stored in Dulbecco's modified Eagle's medium (DMEM, Invitrogen Corporation, Jefferson City, MO, USA) containing 2\% BSA (Sigma, St. Louis, MO, USA), penicillin (100 U/ml, Invitrogen Corporation), and streptomycin $(100 \mathrm{mg} / \mathrm{ml}$, Invitrogen Corporation) until metformin (Sigma) stimulation. A time-dependent dose-response assay was performed to establish the metformin concentration able to stimulate adiponectin expression $(0.1 \mathrm{mmol} / \mathrm{l}, 1 \mathrm{mmol} / \mathrm{l}, 5 \mathrm{mmol} / \mathrm{l}$ and $10 \mathrm{mmol} / \mathrm{l}$ for $1 \mathrm{~h}, 24 \mathrm{~h}$ and $48 \mathrm{~h}$ ). Metformin at $10 \mathrm{mmol} / \mathrm{l}$ for $1 \mathrm{~h}$ and $24 \mathrm{~h}$ was chosen and added to the culture medium after $2 \mathrm{~h}$ of serum starvation. At the end of the stimulation, SAT and VAT were collected and processed for total RNA extraction as described in the following section.

\section{Preparation of Human Preadipocytes}

A fragment of the collected biopsies was cut in small pieces and digested with $1 \mathrm{mg} / \mathrm{ml}$ collagenase type 2 (Sigma) for at least $1 \mathrm{~h}$ at $37^{\circ} \mathrm{C}$. The digested tissue was filtered through a sterile gauze and then a nylon filter (BD Bioscience, Franklin Lakes, NJ, USA). The SVF cells were isolated by centrifugation and then treated with a buffer containing $154 \mathrm{mmol} / \mathrm{l}$ $\mathrm{NH}_{4} \mathrm{Cl}, 10 \mathrm{mmol} / \mathrm{KHCO}$, and $0.1 \mathrm{mmol} / \mathrm{l}$ EDTA for lysis of contaminating red blood cells. SVF cells were then plated and cultured with a medium containing a 1:1 mixture of Ham's F12/DMEM (Invitrogen Corporation) supplemented with $5 \%$ decomplemented foetal bovine serum (FBS; Sigma) and antibiotics (penicillin and streptomycin) until confluence. At confluence, cells were differentiated into mature adipocytes using NH AdipoDiff medium (Miltenyi Biotec Bergisch Gladbach, Germany) for 10 days. In vitro differentiated adipocytes, with clearly visible lipid droplets, were starved in 1:1 mixture of Ham's F12/DMEM without FBS for $2 \mathrm{~h}$ and then stimulated by $10 \mathrm{mmol} / \mathrm{l}$ metformin for $1 \mathrm{~h}$ and $24 \mathrm{~h}$. After stimulation, differentiated SVF were collected and processed for RNA and/or protein extraction.

\section{Total RNA Preparation and cDNA Synthesis}

The total RNA was extracted from whole adipose tissue biopsies (SAT and VAT of 5 obese non-diabetic subjects and SAT of 22 obese patients). All adipose tissue specimens were homogenised in RLT lysis buffer (Rneasy Mini Kit; QIAGEN, Valencia, CA, USA) using a rotator-stator, followed by a chloroform delipidation step. The upper aqueous phase was processed for total RNA extraction using silica-based spin columns (Rneasy Mini Kit). The yield of total SAT/VAT RNA was $1.5-7.0 \mu \mathrm{g} / \mathrm{mg}$ of tissue. The RNA concentration was quantified spectrophotometrically. Total RNA integrity was verified by agarose gel electrophoresis. The RNA from differentiated SVF cells (from SAT and VAT of 5 obese subjects) was extracted using TRIzol Plus RNA Purification Kit (Invitrogen Corporation). The concentration and the integrity were assessed as previously described. The cDNAs were reverse-transcribed with SuperScript III (Invitrogen, Carlsbad, CA,USA) from $1 \mu \mathrm{g}$ of total RNA.

\section{Determination of Gene Expression}

Real-time quantitative PCR (RTqPCR) was used to quantify mRNA copies. For each sample, 10 ng of cDNA template was amplified in duplicate in PCR reactions on an ABI PRISM 7700 using Assay-on-Demand Gene Expression Products (Applied Biosystems, Foster City, CA, USA). TaqMan probes (Applied Biosystems) for adiponectin, CD68 and the housekeeping gene $\beta$-glucuronidase (GUSB) mRNA were labelled with carboxyfluorescein. Analyses were performed with SDS 3 software (Applied Biosystems). For each sample the relative amount of the mRNA of interest was normalized to the amount of GUSB transcript and data were expressed as $2^{-\Delta \Delta \mathrm{CT}}$ (arbitrary units, $\mathrm{AU}$ ).

\section{Protein Extraction and Western Blot Analysis}

Proteins were extracted from differentiated SVF cells and from SAT and VAT explants using RIPA buffer $(150 \mathrm{mmol} / 1 \mathrm{NaCl}, 1 \% \mathrm{NP}-40,0.5 \%$ DOC, $0.1 \%$ SDS, $50 \mathrm{mmol} / 1 \mathrm{Tris}-\mathrm{HCl} \mathrm{pH} 8.0)$ containing a cocktail of protease inhibitors (Roche, Mannheim, Germany). Total protein content was quantified with BCA protein assay kit (PIERCE, Rockford, IL, USA). $30 \mu \mathrm{g}$ of proteins were separated by $12 \%$ SDS-PAGE gel under denaturating conditions and blotted onto nitrocellulose membranes. These membranes were blocked in TBS and 5\% milk for $2 \mathrm{~h}$ at room 
Fig. 1. a Mean $\pm S E$ mRNA expression levels of adiponectin gene in $\operatorname{SAT}(\mathrm{n}=5)$ and VAT $(\mathrm{n}=5)$ explants. Black histograms represent the adiponectin expression in untreated explants. Grey histograms represent adiponectin expression after treatment with metformin

(10 mmol/l) for 1 and 24 h. b Intracellular adiponectin protein content in SAT $(\mathrm{n}=$ 5) and VAT ( $\mathrm{n}=5)$ explants. Black histograms indicate the protein content in untreated explants. Grey histograms indicate the protein content after metformin $(10 \mathrm{mmol} / \mathrm{l})$ treatment in SAT and VAT explants for 1 and $24 \mathrm{~h}$, respectively. Data are expressed as mean \pm SE. A representative Western blot image of adiponectin and actin protein immunodetection is also shown. The adiponectin intracellular protein content was normalised by the intracellular actin protein content. c Adiponectin protein secretion in culture media of SAT $(n=5)$ and VAT $(\mathrm{n}=5)$ explants untreated (black histograms) or treated with metformin $(10 \mathrm{mmol} / \mathrm{l})$ for 1 and $24 \mathrm{~h}$ (grey histograms). Data are expressed as mean \pm $\mathrm{SE}$ (ng/ml/total protein content).

$\mathrm{AU}=$ arbitrary units. $* \mathrm{p}<0.05$ treated explants versus untreated explants.
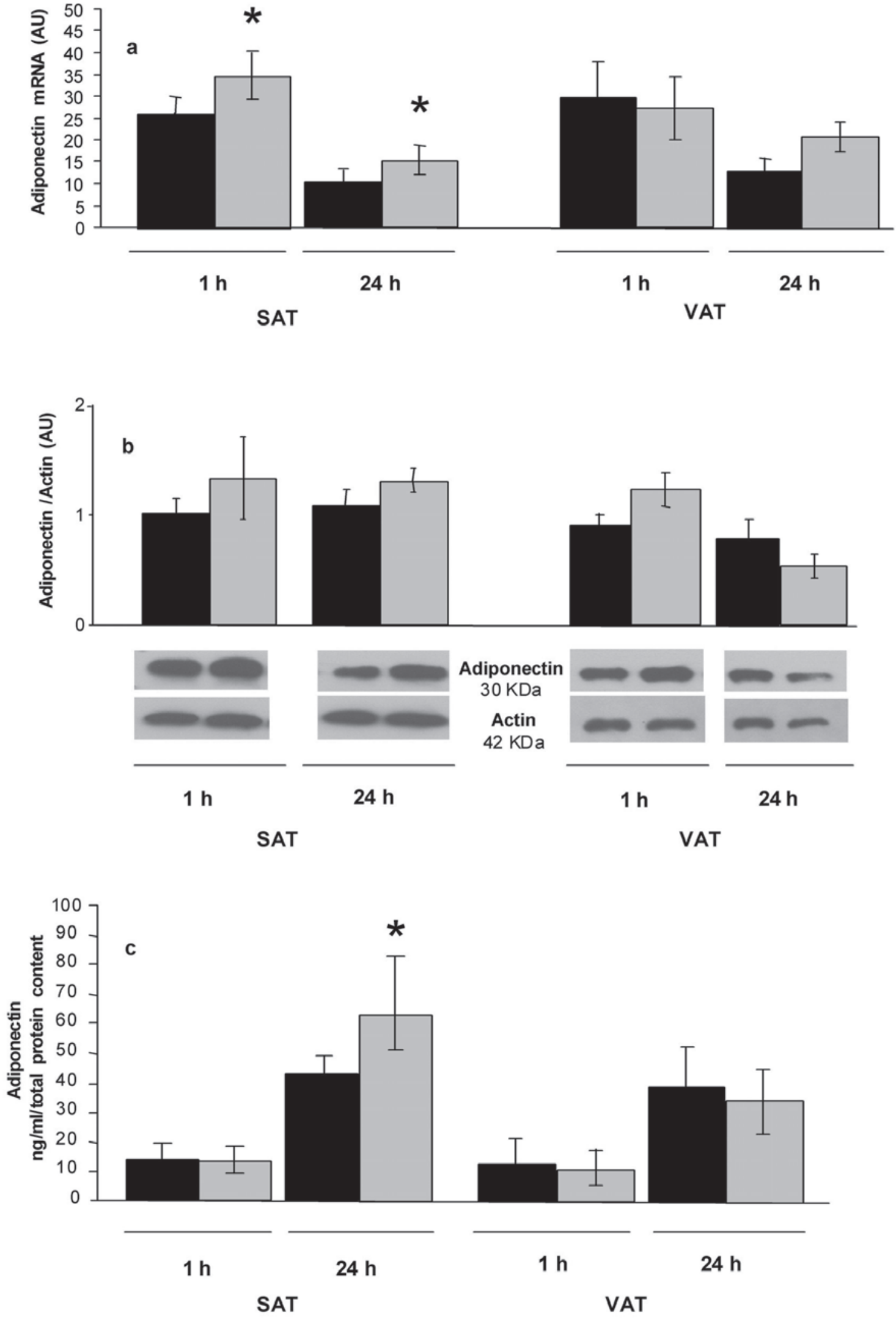
Table 1. Clinical and biochemical characteristics of 22 obese patients who underwent 3 months of metformin + lifestyle (ML intervention group, $\mathrm{n}=12$ ) or placebo + lifestyle intervention (PL intervention group, $\mathrm{n}=10)^{*}$

\begin{tabular}{|c|c|c|c|c|}
\hline & \multicolumn{2}{|c|}{ ML intervention $(\mathrm{n}=12)$} & \multicolumn{2}{|c|}{ PL intervention $(\mathrm{n}=10)$} \\
\hline & before intervention & after intervention & before intervention & after intervention \\
\hline BMI, kg/m² & $39.5 \pm 4.8$ & $35.5 \pm 4.7^{\mathrm{a}}$ & $39.5 \pm 4.6$ & $37.3 \pm 5.3^{\mathrm{a}}$ \\
\hline Waist circumference, $\mathrm{cm}$ & $120.5 \pm 11.2$ & $116.5 \pm 13.2^{\mathrm{a}}$ & $121.0 \pm 9.1$ & $118.4 \pm 9.7^{\mathrm{c}}$ \\
\hline Fat mass / fat-free mass ratio & $0.89 \pm 0.1$ & $0.79 \pm 0.1^{\mathrm{a}}$ & $0.81 \pm 0.2$ & $0.81 \pm 0.2$ \\
\hline Fasting glucose, mg/dl & $115.7 \pm 15.8$ & $100.3 \pm 9.5^{\mathrm{a}}$ & $110.0 \pm 9.7$ & $103.1 \pm 12.0^{c}$ \\
\hline 2-hour glucose, mg/dl & $152.2 \pm 45.9^{\mathrm{b}}$ & $128.2 \pm 40.9$ & $101.5 \pm 55.8$ & $100.7 \pm 43.1$ \\
\hline Fasting insulin, mU/1 & $17.5(13.3-21.0)$ & $10.0(8.1-22.1)$ & $19.3(13.9-26.5)$ & $18.3(11.5-32.4)$ \\
\hline HOMA-IR & $4.6(4.0-5.7)$ & $2.4(2.0-5.9)$ & $5.2(4.1-6.4)$ & $4.4(3.1-9.0)$ \\
\hline HDL cholesterol, mg/dl & $2.8 \pm 1.05$ & $2.5 \pm 0.90$ & $2.3 \pm 0.40$ & $2.3 \pm 0.38$ \\
\hline Triglycerides, mg/dl & $157.0(114.5-196.5)$ & $130.0(101.0-166.2)$ & $133.5(93.2-158.0)$ & $131.0(95.5-185.0)$ \\
\hline Adiponectin, $\mu \mathrm{g} / \mathrm{ml}$ & $5.4(4.4-7.5)^{\mathrm{b}}$ & $5.7(4.7-7.7)$ & $7.8(5.8-10-7)$ & $7.2(6.3-10.7)$ \\
\hline PAS & $4.2 \pm 2.7$ & $7.1 \pm 2.8^{\mathrm{a}}$ & $4.3 \pm 2.5$ & $7.2 \pm 2.9^{\mathrm{a}}$ \\
\hline
\end{tabular}

PAS = Physical Activity Score [28].

*Data are expressed as mean \pm SD except for fasting insulin, HOMA-IR, HDL cholesterol, triglycerides, and adiponectin that are expressed as median (and inter-quartile range).

${ }^{\mathrm{a}} \mathrm{p}<0.01$ versus baseline within the same group.

${ }^{\mathrm{b}} \mathrm{p}<0.05$ versus baseline in PL group.

${ }^{\mathrm{c}} \mathrm{p}<0.05$. temperature, incubated overnight at $4{ }^{\circ} \mathrm{C}$ in the same buffer supplemented with a monoclonal antibody raised against adiponectin (1:5,000; Alexis Biochemical, Grunberg, Germany) and actin (1:15,000; Sigma). The following day membranes were washed with TBS $0.1 \%$ Tween-20 and the secondary antibody (1:4,000, horseradish peroxidase-conjugated anti-mouse antibody; Amersham Biosciences, Little Chalfont, UK) was incubated for $1 \mathrm{~h}$ at room temperature. Enhanced chemiluminescence plus Western blot detection system (Amersham Biosciences) was used for detection. Results were quantified by densitometry using Scion Image Software and normalised on human actin protein content.

\section{Adiponectin Secretion}

Culture media from SAT and VAT explants and from 10 days differentiated SVF cells were collected with and without metformin stimulation and stored at $-80{ }^{\circ} \mathrm{C}$ until use. Adiponectin secretion in the medium was measured by the same assay used for the detection of serum levels (see following section 'Biochemical Measurements').

\section{Biochemical Measurements}

Circulating levels of glucose, cholesterol, and triglycerides were measured using an automated analyzer (Roche Diagnostic). Serum insulin was measured by a chemiluminescent assay (Roche Diagnostic) with intraand inter-assay coefficient of variations of 2.0 and $3.7 \%$. Total adiponectin levels in serum were determined by an enzyme-linked immunoabsorbent assay (B-Bridge International Inc., San Jose, CA, USA) with intra- and inter-assay coefficients of variation of $3.3 \%$ and $7.4 \%$.

\section{Statistical Analysis}

All analyses were performed using SPSS version 16.0 (SPSS, Inc., Chicago, IL, USA). Variables that were not normally distributed were logtransformed before the analysis. Baseline and post-treatment variables within groups and differences between groups were compared using nonparametric Mann-Whitney test. Pearson's analyses were used to evaluate bivariate relationships. Analysis of covariance with corresponding baseline values was used to compare the intervention-induced changes. Wilcoxon's rank-test was used to compare mRNA expression levels, adiponectin protein content as well as secretion in tissue explants and in differentiated adipocytes after metformin treatment. A p value $<0.05$ was considered statistically significant.

\section{Results}

\section{In vitro Effects of Metformin}

To assess if metformin has a direct effect on adiponectin in whole adipose tissue, SAT and VAT explants and differentiated SVF cells were treated with $10 \mathrm{mmol} / \mathrm{l}$ metformin. Two stimulation times were considered: $1 \mathrm{~h}$ as an acute stimulus, and $24 \mathrm{~h}$ as a chronic stimulus. In SAT explants, adiponectin expression increased both after 1-hour and 24-hour treatment with metformin, whereas in VAT explants, adiponectin gene expression did not show significant changes (fig. 1a).

The intracellular protein content did not significantly change in both fat compartments (fig. 1b).

A significant increase in adiponectin secretion was observed after 24-hour treatment with metformin in SAT, but not in VAT explants (fig. 1c).

In differentiated SVF cells from both fat depots, metformin did not change adiponectin expression, protein content, and secretion after $1 \mathrm{~h}$ and $24 \mathrm{~h}$ of stimulation (data not shown).

\section{In vivo Effects of Metformin}

22 patients completed the study. Two patients from the PL group dropped out due to their disagreement to repeat the adipose tissue biopsy at the end of intervention.

Baseline characteristics of the 22 obese patients are summarised in table 1 (before intervention column). Compared to those in the PL group, patients in the ML group were similar in terms of age and sex distribution (52.6 \pm 10.9 vs. $52.2 \pm 11.4$ years and 25 vs. $30 \%$ of males), lipid profile, glucose and HOMA-IR levels. Because of randomisation, the ML group included 4 subjects with OGTT-diagnosed diabetes, 3 with IGT and 4 with IFG, whereas the PL group included 1 subject with OGTT-diagnosed diabetes and 7 with 


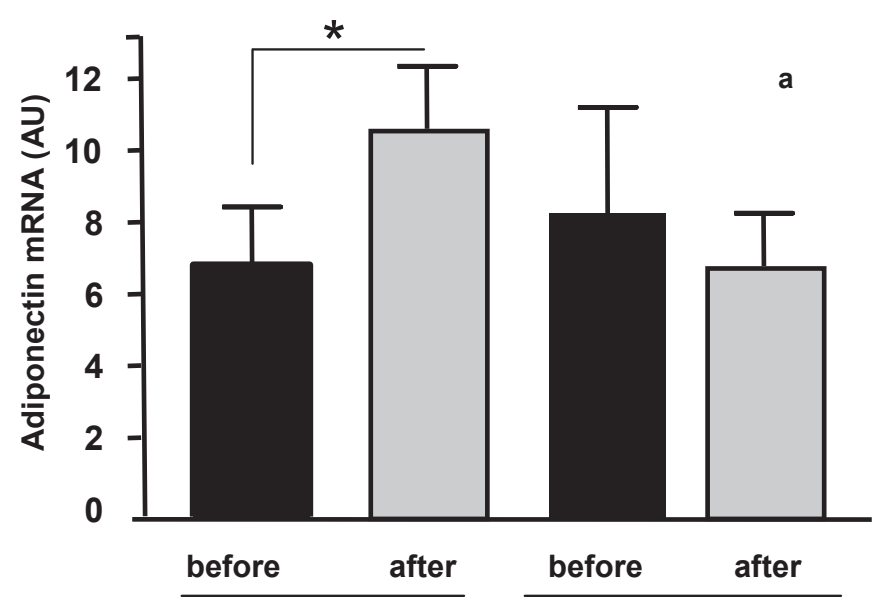

ML PL

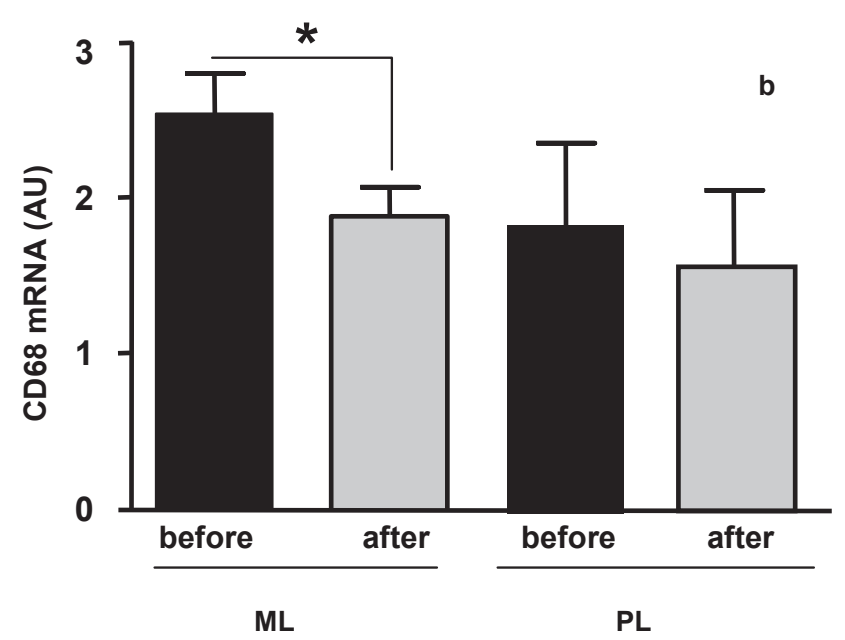

Fig 2. a Adiponectin and b CD68 mRNA expression levels in SAT collected from obese patients before (black histograms) and after (grey histograms) 3 months of metformin + lifestyle intervention (ML, $\mathrm{n}=12$ ) and placebo + lifestyle intervention $(\mathrm{PL}, \mathrm{n}=10)$. Data are expressed as mean \pm SE.

$\mathrm{AU}=$ arbitrary units.

*p $<0.05$ between data before intervention versus after intervention.

IFG. At baseline, subjects in ML group had higher 2-hour glucose and lower serum adiponectin levels $(\mathrm{p}<0.05$ for both).

The post-treatment effects of ML and PL intervention are illustrated in table 1 (after intervention column). In the ML group, the compliance to the exercise program was scored as 'sufficient' and 'good' in 30 and $65 \%$ of the patients, respectively. In the PL group, this same score was 'sufficient' and 'good' in 36 and $61 \%$ of the patients, respectively. At the end of the 3-month treatment, BMI, waist circumference and fasting glucose significantly improved in both groups. Fat mass / fat-free mass ratio significantly decreased in the ML group only $(\mathrm{p}<0.05)$ despite a similar improvement in physical activity score achieved after both interventions.
There was a greater decrease in insulin, HOMA-IR and 2-hour glucose in the ML than in the PL group, but these changes were not significantly different between both groups.

At the end of ML intervention, 2 patients with OGTTdiagnosed diabetes became IGT, and two patients with IGT reverted to normal glucose tolerance (NGT). Four patients with IFG reverted to NGT after PL intervention.

In both groups serum adiponectin did not change significantly after the intervention (table 1). The pattern of SAT adiponectin expression is shown in figure 2. At baseline, SAT adiponectin gene expression was not significantly different between the two groups, and a significant increase $(\mathrm{p}<0.05)$ was observed after the intervention only in the ML group (fig. 2a). Baseline and post-intervention mRNA levels of adiponectin in SAT were not associated with serum adiponectin, BMI, waist circumference, fat mass / fat-free mass ratio and blood pressure as well as with all other metabolic variables considered.

In order to estimate the 'inflammatory status' of the collected SAT in ML and PL patients, we analysed the expression levels of CD68, a commonly used marker for macrophages. At baseline, CD68 expression was higher in the ML than in the PL group SAT, although this difference did not reach statistical significance. The ML intervention induced a significant decrease in CD68 adipose tissue expression (from $2.5 \pm 0.26$ to $1.9 \pm 0.19, \mathrm{p}<0.05$ ) (fig. 2b). The CD68 expression level was unchanged in SAT of patients of the PL group (fig. $2 b$ ).

\section{Discussion}

In the present study, we assessed the effects of metformin on adipose tissue in different experimental models: i) SAT and VAT tissue explants that are composed by adipocytes, preadipocytes, endothelial cells, fibroblasts and infiltrating immune cells, and thus reflect the in vivo environment to which adiponectin production is exposed; ii) adipocytes differentiated in vitro from SVF cells that are synchronized for the maturation rate independently from environmental influence; and iii) whole SAT collected after 3 months metformin therapy (in vivo study).

In SAT explants, we observed a stimulating effect of metformin on adiponectin mRNA expression and secretion. The absence of stimulation in VAT suggests that SAT has a greater sensitivity to metformin action. This finding is consistent with the demonstration that SAT is the only fat depot capable to secrete adiponectin under treatment with another insulin-sensitising agent, pioglitazone [20]. The lack of intracellular adiponectin accumulation suggests that metformin is able to up-regulate adiponectin release by modulating posttranslational events. Supporting this hypothesis, metformin potentiates rosiglitazone-induced decrease in endoplasmic reticulum retention of ERp44 protein [29] that, together with the release protein Erol-1 $\alpha$, modulates intracellular adiponectin content and its secretion [30,31]. 
In contrast to what is observed in adipose tissue explants, metformin did not modify adiponectin expression, protein content, and secretion in adipocytes differentiated in vitro from the SVF cells (data not shown). Thus, it could be hypothesised that the non-adipose components of SAT (i.e. preadipocytes, fibroblasts, infiltrating macrophages, lymphocytes, endothelial cells, etc.) participate in the regulation of metformin effects on adiponectin production and secretion. This hypothesis agrees with the inability of metformin therapy to modify in vivo adiponectin content and secretion in a model of isolated adipocytes of diabetic patients [26]. The possible role of the 'non-adipose components' in the modulation of adiponectin synthesis in SAT is also supported by our in vivo results, demonstrating that macrophage activation (assessed by CD68 expression in SAT samples) decreases after ML intervention. This finding adds another evidence to the anti-inflammatory properties of metformin that have been demonstrated in vitro in human vascular smooth muscle cells, macrophages and endothelial cells, and in vivo in diabetic and non-diabetic subjects [9, 32-34]. Interestingly, addition of metformin to lifestyle intervention provided more metabolic benefits than lifestyle intervention and placebo. The metabolic improvement was associated with an increase in SAT adiponectin expression only in the ML group.

However, the increase in adiponectin adipose tissue expression, was not associated with a similar increase in the circulating levels of this protein. This discrepancy may be explained by assuming that the adiponectin secreted under metformin therapy is maintained within adipose tissue to promote its local autocrine/paracrine beneficial effects [14]. The release of the protein into the circulation is likely a secondstep phenomenon that needs an observation period longer than that established in our study.

It could therefore hypothesised that metformin merely influences tissue availability of adiponectin through a decrease in the local inflammatory state (decrease in CD68 expression). The discrepancy observed in different experimental conditions between adiponectin expression and release as well as serum levels demonstrates that the molecular mechanisms by which adiponectin is synthesized and secreted are complex and still far from being understood [29, 31, 35, 36].

In conclusion, current data demonstrates that in whole human SAT metformin up-regulates adiponectin gene expression, both in vivo and in vitro, and stimulates adiponectin protein secretion in vitro. This effect of metformin on adipose tissue represents an additional mechanism through which this compound may induce clinical benefits. Further studies are required to better understand the molecular pathway of this up-regulation in humans.

\section{Acknowledgments}

The authors thank Dr. Anna Maria Di Blasio for critical reading of the manuscript.

\section{Disclosure Statement}

The authors declare no conflicts of interest.

\section{References}

1 Hunda RS, Krssak M, Dufour S, Laurent D, Lebon V, Chandramouli V, Inzucchi SE, Schumann WC, Petersen KF, Landau BR, Shulman GI: Mechanism by which metformin reduces glucose production in type 2 diabetes. Diabetes 2000;49:2063-2069.

2 Tiikkainen M, Hakkinen AM, Korsheninnikova E, Nyman T, Makimattila S, Yki-Jarvinen H: Effects of rosiglitazone and metformin on liver fat content, hepatic insulin resistance, insulin clearance, and gene expression in adipose tissue in patients with type 2 diabetes. Diabetes 2004:53:2169-2176.

3 Zhang T, He J, Xu C, Zu L, Jiang H, Pu S, Guo $\mathrm{X}, \mathrm{Xu} \mathrm{G}$ : Mechanisms of metformin inhibiting lipolytic response to isoproterenol in primary rat adipocytes. J Mol Endocrinol 2009;42:57-66.

4 Galuska D, Nolte LA, Zierath JR, Wallberg-Henriksson $\mathrm{H}$ : Effect of metformin on insulin-stimulated glucose transport in isolated skeletal muscle obtained from patients with NIDDM. Diabetologia 1994;37:826-832.

5 Hother-Nielsen O, Schmitz O, Andersen PH, Beck-Nielsen H, Pedersen O: Metformin improves peripheral but not hepatic insulin action in obese patients with type II diabetes. Acta Endocrinol (Copenh) 1989;120:257-265.
6 Mithieux G, Rajas F, Zitoun C: Glucose utilization is suppressed in the gut of insulin-resistant high fat-fed rats and is restored by metformin. Biochem Pharmacol 2006;72:1757-1762

7 Marchetti P, Del Guerra S, Marselli L, Lupi R, Masini M, Pollera M, Bugliani M, Boggi U, Vistoli F, Mosca F, Del Prato S: Pancreatic islets from type 2 diabetic patients have functional defects and increased apoptosis that are ameliorated by metformin. J Clin Endocrinol Metab 2004;89:5535-5541.

8 Wiernsperger NF: 50 years later: is metformin a vascular drug with antidiabetic properties? $\mathrm{Br} \mathrm{J}$ Diab Vasc Dis 2007;7:204-210.

9 Song J, Ren P, Zhang L, Wang XL, Chen L, Shen YH: Metformin reduces lipid accumulation in macrophages by inhibiting FOXO1-mediated transcription of fatty acid-binding protein 4 . Biochem Biophys Res Commun 2010;393:89-94.

10 Ben Sahra I, Le Marchand-Brustel Y, Tanti JF, Bost F: Metformin in cancer therapy: a new perspective for an old antidiabetic drug? Mol Cancer Ther 2010;9:1092-1099.

11 Diamanti-Kandarakis E, Christakou CD, Kandaraki E, Economou FN: Metformin: an old medication of new fashion: evolving new molecular mechanisms and clinical implications in polycystic ovary syndrome. Eur J Endocrinol 2010;162:193-212.
12 Yamauchi T, Kamon J, Ito Y, Tsuchida A, Yokomizo T, Kita S, Sugiyama T, Miyagishi M, Hara K, Tsunoda M, Murakami K, Ohteki T, Uchida S, Takekawa S, Waki H, Tsuno NH, Shibata Y, Terauchi Y, Froguel P, Tobe K, Koyasu S, Taira K, Kitamura T, Shimizu T, Nagai R, Kadowaki T: Cloning of adiponectin receptors that mediate antidiabetic metabolic effects. Nature 2003;423:762-769.

13 Maury E, Brichard SM: Adipokine dysregulation, adipose tissue inflammation and metabolic syndrome. Mol Cell Endocrinol 2010;314:1-16.

14 Ohashi K, Parker JL, Ouchi N, Higuchi A, Vita JA, Gokce N, Pedersen AA, Kalthoff C, Tullin S, Sams A, Summer R, Walsh K: Adiponectin promotes macrophage polarization toward an anti-inflammatory phenotype. J Biol Chem 2010;285:6153-6160.

15 Antoniades C, Antonopoulos AS, Tousoulis D, Stefanadis C: Adiponectin: from obesity to cardiovascular disease. Obes Rev 2009;10:269-279.

16 Diez JJ, Iglesias P: The role of the novel adipocytederived hormone adiponectin in human disease. Eur J Endocrinol 2003;148:293-300.

17 Sporrer D, Weber M, Wanninger J, Weigert J, Neumeier M, Stogbauer F, Lieberer E, Bala M, Kopp A, Schaffler A, Buechler C: Adiponectin downregulates CD163 whose cellular and soluble forms are elevated in obesity. Eur J Clin Invest 2009;39:671-679. 
18 Zakikhani M, Dowling RJ, Sonenberg N, Pollak $\mathrm{MN}$ : The effects of adiponectin and metformin on prostate and colon neoplasia involve activation of AMP-activated protein kinase. Cancer Prev Res (Phila Pa) 2008;1:369-375.

19 Kola B, Boscaro M, Rutter GA, Grossman AB, Korbonits M: Expanding role of AMPK in endocrinology. Trends Endocrinol Metab 2006;17:205215.

20 Phillips SA, Ciaraldi TP, Oh DK, Savu MK, Henry RR: Adiponectin secretion and response to pioglitazone is depot dependent in cultured human adipose tissue. Am J Physiol Endocrinol Metab 2008; 295:E842-50.

21 Riera-Guardia N, Rothenbacher D: The effect of thiazolidinediones on adiponectin serum level: a meta-analysis. Diabetes Obes Metab 2008;10:367375.

22 Adamia N, Virsaladze D, Charkviani N, Skhirtladze M, Khutsishvili M: Effect of metformin therapy on plasma adiponectin and leptin levels in obese and insulin resistant postmenopausal females with type 2 diabetes. Georgian Med News 2007;(145):52-55.

23 Mather KJ, Funahashi T, Matsuzawa Y, Edelstein S, Bray GA, Kahn SE, Crandall J, Marcovina S, Goldstein B, Goldberg R, Diabetes Prevention Program: Adiponectin, change in adiponectin, and progression to diabetes in the Diabetes Prevention Program. Diabetes 2008;57:980-986.

24 Jakubowska J, Bohdanowicz-Pawlak A, Milewicz A, Szymczak J, Bednarek-Tupikowska G, Demissie M: Plasma cytokines in obese women with polycystic ovary syndrome, before and after metformin treatment. Gynecol Endocrinol 2008;24:378-384.
25 Sharma PK, Bhansali A, Sialy R, Malhotra S, Pandhi P: Effects of pioglitazone and metformin on plasma adiponectin in newly detected type 2 diabetes mellitus. Clin Endocrinol (Oxf) 2006;65:722-728.

26 Phillips SA, Ciaraldi TP, Kong AP, Bandukwala R, Aroda V, Carter L, Baxi S, Mudaliar SR, Henry RR: Modulation of circulating and adipose tissue adiponectin levels by antidiabetic therapy. Diabetes 2003;52:667-674.

27 Huypens P, Quartier E, Pipeleers D, Van de Casteele M: Metformin reduces adiponectin protein expression and release in 3T3-L1 adipocytes involving activation of AMP activated protein kinase. Eur J Pharmacol 2005;518:90-95.

28 Sinaki M, Kenneth P, Offord P: Physical activity in postmenopausal women: effect on back muscle strength and bone mineral density of the spine. Arch Phys Med Rehabil 1988; 69:277-280.

29 Phillips SA, Kung J, Ciaraldi TP, Choe C, Christiansen L, Mudaliar S, Henry RR: Selective regulation of cellular and secreted multimeric adiponectin by antidiabetic therapies in humans. Am J Physiol Endocrinol Metab 2009;297:E767-73.

30 Schraw T, Wang ZV, Halberg N, Hawkins M, Scherer PE: Plasma adiponectin complexes have distinct biochemical characteristics. Endocrinology 2008;149:2270-2282.

31 Wang ZV, Schraw TD, Kim JY, Khan T, Rajala MW, Follenzi A, Scherer PE: Secretion of the adipocyte-specific secretory protein adiponectin critically depends on thiol-mediated protein retention. Mol Cell Biol 2007;27:3716-3731.
32 Isoda K, Young JL, Zirlik A, MacFarlane LA, Tsuboi N, Gerdes N, Schonbeck U, Libby P: Metformin inhibits proinflammatory responses and nuclear factor-kappaB in human vascular wall cells. Arterioscler Thromb Vasc Biol 2006;26:611-617.

33 Haffner S, Temprosa M, Crandall J, Fowler S, Goldberg R, Horton E, Marcovina S, Mather K, Orchard T, Ratner R, Barrett-Connor E, Diabetes Prevention Program Research Group: Intensive lifestyle intervention or metformin on inflammation and coagulation in participants with impaired glucose tolerance. Diabetes 2005;54:1566-1572.

34 Dandona P, Aljada A, Ghanim H, Mohanty P, Tripathy C, Hofmeyer D, Chaudhuri A: Increased plasma concentration of macrophage migration inhibitory factor (MIF) and MIF mRNA in mononuclear cells in the obese and the suppressive action of metformin. J Clin Endocrinol Metab 2004;89: 5043-5047.

35 Wolf G: New insights into thiol-mediated regulation of adiponectin secretion. Nutr Rev 2008;66:642-645.

36 Perrini S, Laviola L, Cignarelli A, Melchiorre M, De Stefano F, Caccioppoli C, Natalicchio A, Orlando MR, Garruti G, De Fazio M, Catalano G, Memeo V, Giorgino R, Giorgino F: Fat depotrelated differences in gene expression, adiponectin secretion, and insulin action and signalling in human adipocytes differentiated in vitro from precursor stromal cells. Diabetologia 2008;51:155-164. 